\title{
Brain death and postmortem organ donation: report of a questionnaire from the CENTER-TBI study
}

\author{
Ernest van Veen ${ }^{1,2,3}$, Mathieu van der Jagt ${ }^{1}$, Maryse C. Cnossen², Andrew I. R. Maas ${ }^{4}$, Inez D. de Beaufort ${ }^{3}$, \\ David K. Menon ${ }^{5}$, Giuseppe Citerio ${ }^{6,7}$, Nino Stocchetti ${ }^{8,9}$, Wim J. R. Rietdijk ${ }^{1}$, Jeroen T. J. M. van Dijck ${ }^{10}$, \\ Erwin J. O. Kompanje ${ }^{1,3^{*}}$ and CENTER-TBI investigators and participants
}

\begin{abstract}
Background: We aimed to investigate the extent of the agreement on practices around brain death and postmortem organ donation.

Methods: Investigators from 67 Collaborative European NeuroTrauma Effectiveness Research in Traumatic Brain Injury (CENTER-TBI) study centers completed several questionnaires (response rate: 99\%).

Results: Regarding practices around brain death, we found agreement on the clinical evaluation (prerequisites and neurological assessment) for brain death determination (BDD) in 100\% of the centers. However, ancillary tests were required for BDD in $64 \%$ of the centers. BDD for nondonor patients was deemed mandatory in $18 \%$ of the centers before withdrawing life-sustaining measures (LSM). Also, practices around postmortem organ donation varied. Organ donation after circulatory arrest was forbidden in $45 \%$ of the centers. When withdrawal of LSM was contemplated, in $67 \%$ of centers the patients with a ventricular drain in situ had this removed, either sometimes or all of the time.

Conclusions: This study showed both agreement and some regional differences regarding practices around brain death and postmortem organ donation. We hope our results help quantify and understand potential differences, and provide impetus for current dialogs toward further harmonization of practices around brain death and postmortem organ donation.
\end{abstract}

Keywords: Traumatic brain injury, Brain death, Ethics, Postmortem organ donation, Withdrawing life-sustaining measures, Ventricular drainage

\section{Background}

Before the 1950s, death was only determined using cardiovascular criteria. Due to advances in critical care medicine, especially mechanical ventilation, a new clinical state was observed in 1958 (i.e., "coma dépassé") [1]. Although the systemic circulation was intact, the brain showed no objective evidence of function. This observation gave rise to the question of what "coma

\footnotetext{
* Correspondence: e.j.o.kompanje@erasmusmc.nl

'Department of Intensive Care, Erasmus University Medical Center, Rotterdam, the Netherlands

${ }^{3}$ Department of Medical Ethics and Philosophy of Medicine, Erasmus University Medical Center, Rotterdam, the Netherlands

Full list of author information is available at the end of the article
}

dépassé" meant. The successful transplantation of kidneys from a "coma dépassé" patient (1965) subsequently led to the first accepted standard for the confirmation of brain death in 1968 [2]. In 1981, the Uniform Determination of Death Act made death determined by neurological and cardiovascular criteria equivalent [3]. The American Academy of Neurology (AAN) in 1995 published guidelines for brain death determination (BDD) [4], and updated these in 2010 [5]. In 2008, the Academy of Medical Royal Colleges in the United Kingdom (UK) provided broader guidance on the determination of death in a range of circumstances, including BDD [6].

Brain death and postmortem organ donation are closely linked. Also, an important, and not well investigated, issue

(c) The Author(s). 2018 Open Access This article is distributed under the terms of the Creative Commons Attribution 4.0 International License (http://creativecommons.org/licenses/by/4.0/), which permits unrestricted use, distribution, and 
regarding circulatory arrest organ donation is the hands-off time after circulatory arrest. Practices around all of these mentioned topics are delicate. Thus, inconsistencies between centers can be confusing for the general public, and could expose clinicians to accusations of unethical practice. Consensus regarding practices around brain death and postmortem organ donation could prevent these inconsistencies. To facilitate this consensus, the first step is to document potential differences.

The Collaborative European NeuroTrauma Effectiveness Research in Traumatic Brain Injury (CENTER-TBI, www.center-tbi.eu) study addressed this issue. The CENTER-TBI study used questionnaires to create "provider profiles" of participating neurotrauma centers. One of these questionnaires intended to address specific practices around brain death and postmortem organ donation that currently provoke international discussion. Using this questionnaire, we aimed to quantify and understand potential differences, and provide impetus for current dialogs toward further harmonization of practices around brain death and postmortem organ donation. Regarding brain death, we investigated: criteria used for $\mathrm{BDD}$; and the necessity of BDD before withdrawing life-sustaining measures (LSM). As for postmortem organ donation, we investigated: removal of the ventricular drain while continuing other LSM; the possibility for circulatory arrest organ donation; and the hands-off time after circulatory arrest.

\section{Methods}

\section{CENTER-TBI and study sample}

The CENTER-TBI study includes a prospective observational study on traumatic brain injury (TBI) $[7,8]$. The investigators connected to this study collect data on patient characteristics, management, and outcomes in important centers from 20 countries across Europe and Israel. Investigators from all participating centers in the CENTER-TBI study were asked to complete several questionnaires. Centers were located in Austria $(N=2)$, Belgium $(N=4)$, Bosnia and Herzegovina $(N=2)$, Denmark $(N=2)$, Finland $(N=2)$, France $(N=7)$, Germany $(N=4)$, Hungary $(N=2)$, Israel $(N=2)$, Italy $(N=8)$, Latvia $(N=3)$, Lithuania $(N=2)$, the Netherlands $(N=7)$, Norway $(N=3)$, Romania $(N=1)$, Serbia $(N=1)$, Spain $(N=4)$, Sweden $(N=2)$, Switzerland $(N=1)$, and the UK $(N=8)$.

\section{Questionnaire development and administration}

More detailed information about the development, administration, and content of the questionnaires is available from an earlier publication by Cnossen et al. [9].

The topics covered in the current study are summarized in Table 1. A complete overview of the questionnaires for this study can be found in Additional file 1:
Questionnaire 1 (questions 1, 4, 8, and 9), 7 (questions 2 and 4), and 8 (questions 9 and 11-15). In the questionnaires, we explicitly asked for the "general policy" according to the investigators. We defined this as the local standards used in more than $75 \%$ of patients, recognizing that there might be exceptions. Most questions made use of categorical answer categories. For some questions, the investigators had the option to fill in an answer that could be different from one of the options provided. These answers were marked as "other" and consisted of free text responses. Where these free text responses from different investigators were sufficiently similar, we sought to combine them to provide additional categorical responses. We did this to facilitate summary descriptive statistics.

\section{Analyses}

We used descriptive statistics to describe our outcomes. We calculated frequencies and percentages for all variables related to the number of responses for that question. Centers at which the investigator did not respond to every question remained in our study, in order to keep groups for descriptive statistics as large as possible. The response rates per question are presented in Table 1. We grouped countries into seven regions: Baltic States (Latvia and Lithuania), Eastern Europe (Bosnia and Herzegovina, Hungary, Romania, and Serbia), Israel, Northern Europe (Denmark, Finland, Norway, and Sweden), Southern Europe (Italy and Spain), the United Kingdom, and Western Europe (Austria, Belgium, France, Germany, the Netherlands, and Switzerland). We examined potential differences between and within regions.

\section{Results}

\section{Center characteristics}

Of the 68 centers, investigators from 67 centers participated in the questionnaires (response rate: 99\%) and were included in the analysis. The participating centers were mainly academic centers $(N=61,91 \%)$, designated as a level I or II trauma center $(N=49,73 \%)$. The average number of beds in the participating centers was 1187, of which on average 39 were intensive care unit (ICU) beds. The average number of annual treatments per ICU in 2013 was 1408 , of which on average 130 were TBI patients.

\section{Practices around brain death When do you declare a patient brain dead?}

We found agreement on the clinical evaluation (prerequisites and neurological assessment) for BDD in 100\% of the centers. The clinical evaluation for BDD included: a Glasgow Coma Scale (GCS) of three, absence of brain stem reflexes, no respiratory efforts in response to an apnea test, and absence of confounding factors to 
Table 1 Topics covered, related questions for each topic, and response rate per question

\begin{tabular}{|c|c|c|}
\hline Topics covered in this study & Questions related to this topic & $\begin{array}{l}\text { Response rate, } \\
N(\%)\end{array}$ \\
\hline \multicolumn{3}{|l|}{ Practices around brain death } \\
\hline Criteria for BDD & When do you declare a patient brain dead? & $67(99 \%)$ \\
\hline Brain death and withdrawal of LSM & $\begin{array}{l}\text { Must the patient, who is not suitable for organ donation, be declared } \\
\text { brain dead before withdrawing life-sustaining measures? }\end{array}$ & $67(99 \%)$ \\
\hline \multicolumn{3}{|l|}{ Practices around postmortem organ donation } \\
\hline Donation after circulatory death & $\begin{array}{l}\text { Would you consider organ donation after circulatory arrest in a } \\
\text { patient in whom mechanical ventilation will be withdrawn, but who } \\
\text { is not brain dead? }\end{array}$ & $66(97 \%)$ \\
\hline Ventricular drain removal and organ donation & $\begin{array}{l}\text { If the decision is made to withdraw life-sustaining measures, in a pa- } \\
\text { tient with high intracranial pressure, but who is not brain dead, } \\
\text { would you remove the ventricular drain (for CSF drainage), but con- } \\
\text { tinue other life-sustaining measures in the hope that the patient will } \\
\text { become brain dead and thereby becomes a suitable candidate for } \\
\text { organ donation? }\end{array}$ & $67(99 \%)$ \\
\hline \multirow[t]{2}{*}{$\begin{array}{l}\text { Declaration of death and hands-off time in } \\
\text { donors and nondonors }\end{array}$} & $\begin{array}{l}\text { After withdrawal of mechanical ventilation and after circulatory arrest, } \\
\text { when exactly do you declare the patient dead in case of a circulatory } \\
\text { death organ donor? }\end{array}$ & $64(94 \%)$ \\
\hline & $\begin{array}{l}\text { After withdrawal of mechanical ventilation and after circulatory arrest, } \\
\text { after how many minutes circulatory arrest do you declare the patient } \\
\text { dead in cases not suitable as organ donor? }\end{array}$ & $66(97 \%)$ \\
\hline
\end{tabular}

$B D D$ brain death determination, CSF cerebrospinal fluid, LSM life-sustaining measures

evaluate consciousness (e.g., hypothermia). However, ancillary tests were required for BDD in 43 (64\%) centers (Table 2).

In three regions (43\%; Israel, Southern Europe, and the $\mathrm{UK})$, the same criteria for BDD were used in every center of the same region. In centers from Northern Europe and the UK, ancillary tests were rarely used for BDD $(N$ $=2,22 \%$ and $N=0,0 \%$, respectively).
Must the patient, who is not suitable for organ donation, be declared brain dead before withdrawing LSM?

The declaration of brain death in nondonor patients was mandatory before withdrawing LSM in 12 (18\%) centers. In $41(61 \%)$ centers, a poor prognosis as assessed by the treating physician(s) was considered sufficient. In 9 (13\%) centers, a GCS score of three, fixed dilated pupils, and absence of confounders could motivate withdrawing LSM (Table 2).

Table 2 Practices around brain death

\begin{tabular}{|c|c|c|c|c|c|c|c|c|}
\hline \multirow[b]{2}{*}{ Answer } & \multicolumn{8}{|l|}{ Region } \\
\hline & $\begin{array}{l}\text { Sample } \\
\text { total } \\
(N=67)\end{array}$ & $\begin{array}{l}\text { Baltic } \\
\text { States } \\
(N=5)\end{array}$ & $\begin{array}{l}\text { Eastern } \\
\text { Europe } \\
(N=6)\end{array}$ & $\begin{array}{l}\text { Israel } \\
(N= \\
2)\end{array}$ & $\begin{array}{l}\text { Northern } \\
\text { Europe } \\
(N=9)\end{array}$ & $\begin{array}{l}\text { Southern } \\
\text { Europe } \\
(N=12)\end{array}$ & $\begin{array}{l}\text { United } \\
\text { Kingdom } \\
(N=8)\end{array}$ & $\begin{array}{l}\text { Western } \\
\text { Europe } \\
(N=25)\end{array}$ \\
\hline \multicolumn{9}{|l|}{ When do you declare a patient brain dead? } \\
\hline $\begin{array}{l}\text { With GCS 3, fixed dilated pupils, and no confounding factors } \\
\text { (e.g., hypothermia, barbiturates) }\end{array}$ & 0 & 0 & 0 & 0 & 0 & 0 & 0 & 0 \\
\hline $\begin{array}{l}\text { With GCS } 3 \text { and absent brain stem reflexes, and no } \\
\text { confounding factors }\end{array}$ & 0 & 0 & 0 & 0 & 0 & 0 & 0 & 0 \\
\hline $\begin{array}{l}\text { With GCS 3, absent brain stem reflexes and apnea, and no } \\
\text { confounding factors }\end{array}$ & 31 & 20 & 17 & 0 & 78 & 0 & 88 & 20 \\
\hline $\begin{array}{l}\text { With GCS 3, absent brain stem reflexes, apnea and ancillary } \\
\text { test(s) (e.g., EEG or cerebral angiography), and absence of } \\
\text { confounding factors }\end{array}$ & 64 & 80 & 83 & 100 & 22 & 100 & 0 & 72 \\
\hline Per national protocol ${ }^{\mathrm{a}}$ & 4 & 0 & 0 & 0 & 0 & 0 & 13 & 8 \\
\hline \multicolumn{9}{|c|}{ Must the patient, who is not suitable for organ donation, be declared brain dead before withdrawing LSM? } \\
\hline No, the prospect of a very poor prognosis can be enough & 61 & 0 & 17 & 0 & 78 & 42 & 100 & 80 \\
\hline $\begin{array}{l}\text { No, GCS } 3 \text { and fixed dilated pupils and no confounders is } \\
\text { enough to stop treatment }\end{array}$ & 13 & 0 & 0 & 50 & 22 & 8 & 0 & 20 \\
\hline Yes, this is mandatory by law in my country & 18 & 80 & 17 & 50 & 0 & 50 & 0 & 0 \\
\hline Yes, it is not mandatory by law, but I always do that to be sure & 7 & 20 & 67 & 0 & 0 & 0 & 0 & 0 \\
\hline
\end{tabular}

Data presented as percentage

EEG electroencephalography, GCS Glasgow Coma Scale, LSM life-sustaining measures

${ }^{a}$ Additional categorical responses, while free text responses were sufficiently similar. This does not mean that the other centers do not follow their national protocol 


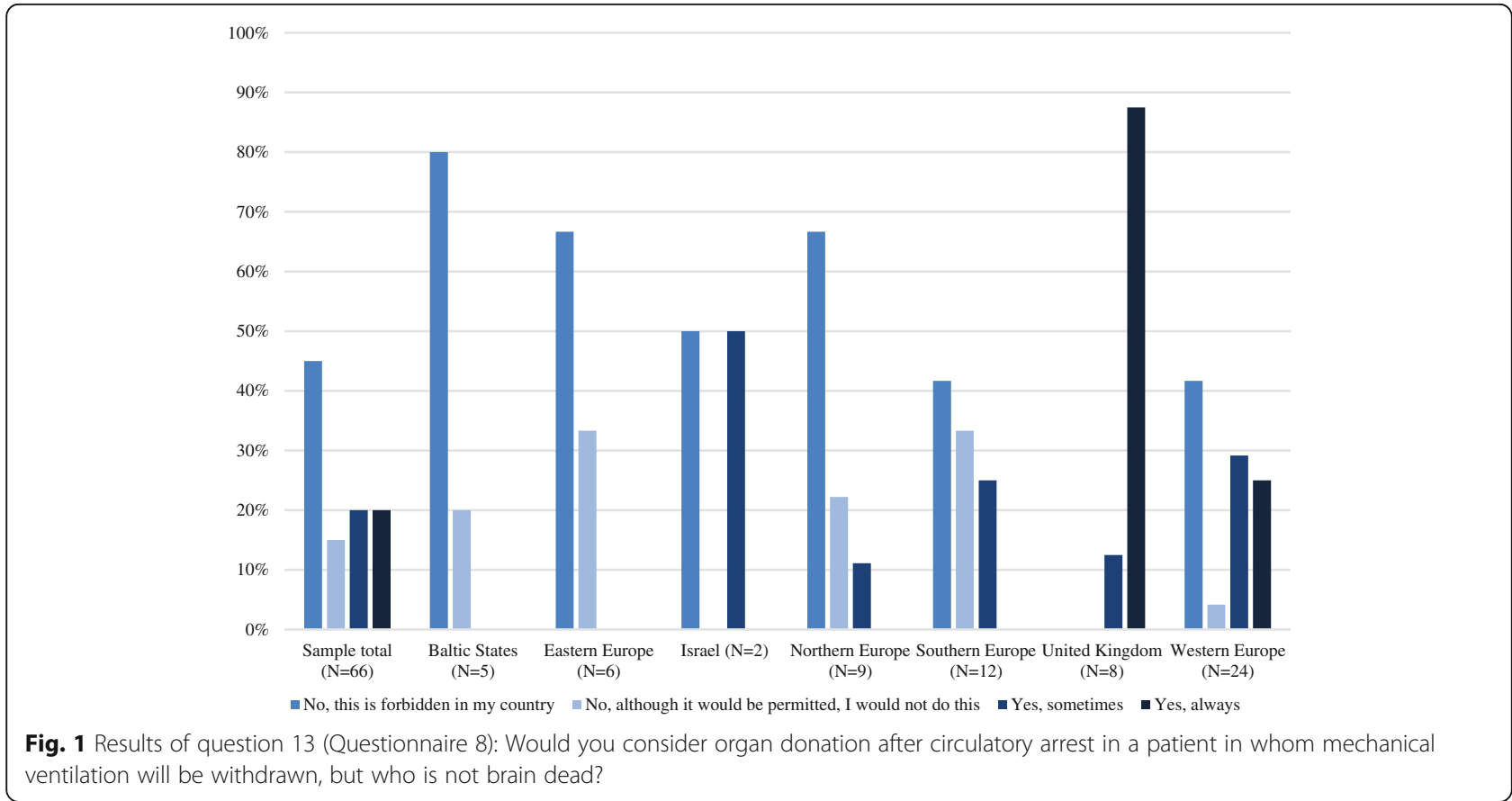

In all centers in the Baltic States $(N=5)$, nondonor patients were declared brain dead before withdrawing LSM. In several centers in Eastern Europe and Southern Europe $(N=1,17 \%$ and $N=6,50 \%$, respectively), it was mandatory to declare a patient brain dead before withdrawing LSM in nondonor patients, whereas in other centers from the same region this was not mandatory.
Practices around postmortem organ donation Would you consider organ donation after circulatory arrest in a patient in whom mechanical ventilation will be withdrawn, but who is not brain dead?

Organ donation after circulatory arrest was forbidden in $30(45 \%)$ centers (Fig. 1 and Table 3 ).

In all centers in the UK $(N=8)$, postmortem organ donation after circulatory arrest was approved. In centers

Table 3 Practices around circulatory arrest organ donation and ventricular drain removal

\begin{tabular}{|c|c|c|c|c|c|c|c|c|}
\hline \multirow[b]{2}{*}{ Answer } & \multicolumn{8}{|l|}{ Region } \\
\hline & $\begin{array}{l}\text { Sample } \\
\text { total } \\
(N=66)\end{array}$ & $\begin{array}{l}\text { Baltic } \\
\text { States } \\
(N=5)\end{array}$ & $\begin{array}{l}\text { Eastern } \\
\text { Europe } \\
(N=6)\end{array}$ & $\begin{array}{l}\text { Israel } \\
(N= \\
2)\end{array}$ & $\begin{array}{l}\text { Northern } \\
\text { Europe } \\
(N=9)\end{array}$ & $\begin{array}{l}\text { Southern } \\
\text { Europe } \\
(N=12)\end{array}$ & $\begin{array}{l}\text { United } \\
\text { Kingdom } \\
(N=8)\end{array}$ & $\begin{array}{l}\text { Western } \\
\text { Europe } \\
(N=24)\end{array}$ \\
\hline \multicolumn{9}{|c|}{ Would you consider organ donation after circulatory arrest in a patient in whom mechanical ventilation will be withdrawn, but who is not brain dead } \\
\hline No, this is forbidden in my country & 45 & 80 & 67 & 50 & 67 & 42 & 0 & 42 \\
\hline $\begin{array}{l}\text { No, although it would be permitted, } \\
\text { I would not do this }\end{array}$ & 15 & 20 & 33 & 0 & 22 & 33 & 0 & 4 \\
\hline Yes, sometimes & 20 & 0 & 0 & 50 & 11 & 25 & 13 & 29 \\
\hline \multirow[t]{2}{*}{ Yes, always } & 20 & 0 & 0 & 0 & 0 & 0 & 88 & 25 \\
\hline & $\begin{array}{l}\text { Sample } \\
\text { total } \\
(N=67)\end{array}$ & $\begin{array}{l}\text { Baltic } \\
\text { States } \\
(N=5)\end{array}$ & $\begin{array}{l}\text { Eastern } \\
\text { Europe } \\
(N=6)\end{array}$ & $\begin{array}{l}\text { Israel } \\
(N= \\
2)\end{array}$ & $\begin{array}{l}\text { Northern } \\
\text { Europe } \\
(N=9)\end{array}$ & $\begin{array}{l}\text { Southern } \\
\text { Europe } \\
(N=12)\end{array}$ & $\begin{array}{l}\text { United } \\
\text { Kingdom } \\
(N=8)\end{array}$ & $\begin{array}{l}\text { Western } \\
\text { Europe } \\
(N=25)\end{array}$ \\
\hline \multicolumn{9}{|c|}{$\begin{array}{l}\text { If the decision is made to withdraw life-sustaining measures, in a patient with high intracranial pressure, but who is not brain dead, would you } \\
\text { remove the ventricular drain (for CSF drainage), but continue other life-sustaining measures in the hope that the patient will become brain dead } \\
\text { and then becomes a suitable candidate for organ donation? }\end{array}$} \\
\hline No, never & 33 & 80 & 33 & 0 & 0 & 17 & 88 & 28 \\
\hline Yes, sometimes & 51 & 20 & 50 & 100 & 100 & 50 & 13 & 48 \\
\hline Yes, always & 16 & 0 & 17 & 0 & 0 & 33 & 0 & 24 \\
\hline
\end{tabular}

Data presented as percentage

CSF cerebrospinal fluid 
in the Baltic States, Eastern Europe, and Northern Europe, organ donation after circulatory arrestwas often forbidden $(N=4,80 \% ; N=4,67 \%$ and $N=6,67 \%$ respectively).

\section{If the decision is made to withdraw life-sustaining measures, in a patient with high intracranial pressure, but who is not brain dead, would you remove the ventricular drain (for CSF drainage), but continue other life-sustaining measures in the hope that the patient will become brain dead and thereby becomes a suitable candidate for organ donation?}

In $45(67 \%)$ centers, the ventricular drain was sometimes or always removed. In 11 of these 45 centers ( $16 \%$ of the Sample total), the ventricular drain was always removed while continuing other LSM. In 22 (33\%) centers, the ventricular drain was never removed while continuing other LSM (Fig. 2 and Table 3).

In $4(80 \%)$ centers in the Baltic States and in $7(88 \%)$ centers in the UK, the ventricular drain was never removed. In all centers from Israel $(N=2)$ and Northern Europe $(N=9)$, the ventricular drain was "sometimes" removed.

\section{After withdrawal of mechanical ventilation and after circulatory arrest, when exactly do you declare the patient dead in case of a circulatory death organ donor, and in cases not suitable as an organ donor?}

In the case of a circulatory death organ donor, it was most common $(N=15,23 \%)$ to declare the patient dead after 5 -min "flatliner-ECG". In cases not suitable as an organ donor, it was most common $(N=21,32 \%)$ to declare the patient dead directly after detection of a "flatliner-ECG" on the monitor (Table 4).

In all centers in Israel, nondonor patients were declared dead directly after detection of a "flatliner-ECG" on the monitor. No other region had the same answer in every center concerning the declaration of death in donor and nondonor patients.

\section{Discussion}

We aimed to investigate specific practices that currently provoke international discussion in the area of brain death and postmortem organ donation. We aimed to quantify and understand potential differences, and provide impetus for current dialogs toward further harmonization of practices around brain death and postmortem organ donation.

Taking all results together, we found agreement on the clinical evaluation (prerequisites and neurological assess ment) for brain death determination (BDD) across regions. In addition to this clinical evaluation, ancillary tests were required for BDD in $64 \%$ of the centers. BDD was deemed mandatory before withdrawal of life-sustaining measures (LSM) even outside the context of organ donation in 18\% of the centers. As for practices around postmortem organ donation across regions, in $67 \%$ of the centers a ventricular drain was sometimes or always removed while other LSM were continued. Last, in $45 \%$ of the centers organ donation after circulatory arrest was forbidden.

We found important agreement and some differences regarding practices around brain death. Due to the broad

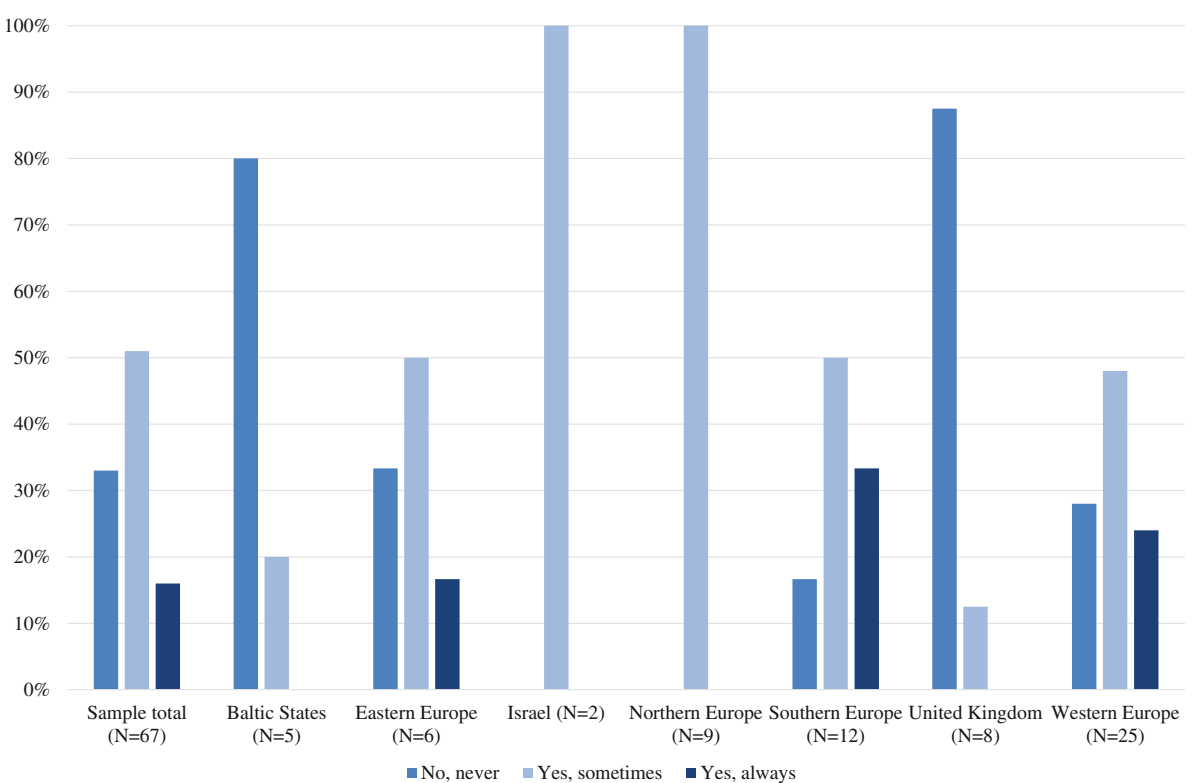

Fig. 2 Results of question 9 (Questionnaire 8): If the decision is made to withdraw life-sustaining measures, in a patient with high intracranial pressure, but who is not brain dead, would you remove the ventricular drain (for CSF drainage), but continue other life-sustaining measures in the hope that the patient will become brain dead and thereby becomes a suitable candidate for organ donation? 
Table 4 Practices around the hands-off time after circulatory arrest

\begin{tabular}{|c|c|c|c|c|c|c|c|c|}
\hline \multirow[b]{2}{*}{ Answer } & \multicolumn{8}{|l|}{ Region } \\
\hline & $\begin{array}{l}\text { Sample } \\
\text { total } \\
(N=64)\end{array}$ & $\begin{array}{l}\text { Baltic } \\
\text { States } \\
(N=5)\end{array}$ & $\begin{array}{l}\text { Eastern } \\
\text { Europe } \\
(N=6)\end{array}$ & $\begin{array}{l}\text { Israel } \\
(N= \\
2)\end{array}$ & $\begin{array}{l}\text { Northern } \\
\text { Europe } \\
(N=9)\end{array}$ & $\begin{array}{l}\text { Southern } \\
\text { Europe } \\
(N=12)\end{array}$ & $\begin{array}{l}\text { United } \\
\text { Kingdom } \\
(N=8)\end{array}$ & $\begin{array}{l}\text { Western } \\
\text { Europe } \\
(N=22)\end{array}$ \\
\hline
\end{tabular}

After withdrawal of mechanical ventilation and after circulatory arrest, when exactly do you declare the patient dead in case of a circulatory death organ donor?

\begin{tabular}{|c|c|c|c|c|c|c|c|c|}
\hline $\begin{array}{l}\text { Directly after circulatory arrest determined after a } \\
\text { "flatliner-ECG" on the monitor }\end{array}$ & 16 & 40 & 0 & 50 & 11 & 8 & 0 & 23 \\
\hline After 1-min "flatliner-ECG" indicating circulatory arrest & 5 & 0 & 0 & 50 & 0 & 8 & 0 & 5 \\
\hline After 2-min "flatliner-ECG" & 2 & 0 & 0 & 0 & 0 & 0 & 0 & 5 \\
\hline After 5-min "flatliner-ECG" & 23 & 20 & 33 & 0 & 11 & 17 & 50 & 23 \\
\hline After 10-min "flatliner-ECG" & 5 & 20 & 17 & 0 & 0 & 0 & 0 & 5 \\
\hline $\begin{array}{l}\text { After loss of pulsatile arterial curve on the invasive } \\
\text { arterial blood pressure tracing }\end{array}$ & 6 & 20 & 17 & 0 & 0 & 0 & 0 & 9 \\
\hline After 20-min "flatliner-ECG"a & 11 & 0 & 0 & 0 & 0 & 58 & 0 & 0 \\
\hline Not done in our hospital/country ${ }^{a}$ & 19 & 0 & 17 & 0 & 78 & 0 & 0 & 18 \\
\hline \multirow[t]{2}{*}{ Other, please specify ${ }^{\mathrm{b}}$} & 14 & 0 & 17 & 0 & 0 & 8 & 50 & 14 \\
\hline & $\begin{array}{l}\text { Sample } \\
\text { total } \\
(N=66)\end{array}$ & $\begin{array}{l}\text { Baltic } \\
\text { States } \\
(N=5)\end{array}$ & $\begin{array}{l}\text { Eastern } \\
\text { Europe } \\
(N=6)\end{array}$ & $\begin{array}{l}\text { Israel } \\
(N= \\
2)\end{array}$ & $\begin{array}{l}\text { Northern } \\
\text { Europe } \\
(N=9)\end{array}$ & $\begin{array}{l}\text { Southern } \\
\text { Europe } \\
(N=12)\end{array}$ & $\begin{array}{l}\text { United } \\
\text { Kingdom } \\
(N=8)\end{array}$ & $\begin{array}{l}\text { Western } \\
\text { Europe } \\
(N=24)\end{array}$ \\
\hline
\end{tabular}

After withdrawal of mechanical ventilation and after circulatory arrest, after how many minutes circulatory arrest do you declare the patient dead in cases not suitable as organ donor?

\begin{tabular}{|c|c|c|c|c|c|c|c|c|}
\hline $\begin{array}{l}\text { Directly after circulatory arrest determined after a } \\
\text { "flatliner-ECG" on the monitor }\end{array}$ & 32 & 40 & 17 & 100 & 11 & 17 & 13 & 50 \\
\hline After 1-min "flatliner-ECG" indicating circulatory arrest & 5 & 0 & 0 & 0 & 0 & 0 & 0 & 13 \\
\hline After 2-min "flatliner-ECG" & 0 & 0 & 0 & 0 & 0 & 0 & 0 & 0 \\
\hline After 5-min "flatliner-ECG" & 23 & 20 & 17 & 0 & 22 & 25 & 38 & 21 \\
\hline After 10-min "flatliner-ECG" & 6 & 20 & 33 & 0 & 0 & & 0 & 0 \\
\hline $\begin{array}{l}\text { After loss of pulsatile arterial curve on the invasive } \\
\text { arterial blood pressure tracing }\end{array}$ & 6 & 20 & 33 & 0 & 11 & 0 & 0 & 0 \\
\hline After 20-min "flatliner-ECG"a & 9 & 0 & 0 & 0 & 0 & 50 & 0 & 0 \\
\hline Not done in our hospital/country ${ }^{a}$ & 8 & 0 & 0 & 0 & 33 & 0 & 0 & 8 \\
\hline Other, please specifyc & 12 & 0 & 0 & 0 & 22 & 0 & 50 & 8 \\
\hline
\end{tabular}

\section{Data presented as percentage}

EEG electroencephalography

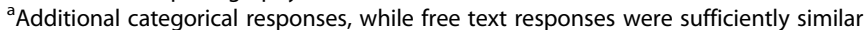

bSpecifications filled in under "other": "two minutes after loss of pulsatile arterial curve on the invasive arterial blood pressure tracing"; "after 3 min"; "No carotid pulses and apnoea"; "absence central pulse for 5 mins confirmed by observation for further 5 mins"; "National guidance 5 mins mechanical asystole"; "apnea test positivity"; "according to the Dutch law on organ donation"; "Protokollbogen zur Feststellung des irreversiblen Hirnfunktionsausfalls"; "at the beginning of the commission observation ( $6 \mathrm{~h}$ before)"

"Specifications filled in under "other": "Control 10 min later"; "After clinical death diagnosis: listen to heart sound, examination of pupils"; "At decision of the physician"; "No carotid pulses and apnoea"; "absence central pulse for 5 mins confirmed by observation for further 5 mins"; "apnea test positivity"; "according to the Dutch law on organ donation"; "Protokollbogen zur Feststellung des irreversiblen Hirnfunktionsausfalls"; "at the beginning of the commission observation (6 h before)"

categorical answer possibilities provided, the application of these findings is limited. First, agreement existed in all centers on the clinical evaluation for BDD, namely a Glasgow Coma Scale (GCS) of three, absence of brain stem reflexes, no respiratory efforts in response to an apnea test, and absence of confounding factors to evaluate consciousness. This is promising, in the light of recent calls to reach a worldwide consensus on how to determine brain death [10]. However, in addition to this clinical evaluation, ancillary tests were reported to be required for BDD in two thirds of centers. These differences in the use of ancillary tests are in line with previous literature [11-19]. Interestingly, however, there have been calls to abandon ancillary tests for BDD [20]. In the majority of centers from Northern Europe and the United Kingdom (UK), ancillary tests were not mandatory for BDD. This is in line with the study by Wahlster et al. [11]. These discrepancies may suggest differences in ethical principles and regulatory practice between centers. In some centers it was mandatory to declare nondonor patients brain dead before 
withdrawing life-sustaining measures (LSM). Withdrawal of LSM and the declaration of brain death are two different processes. The obligation of BDD before limiting treatment is debatable, since many non-brain dead patients may have a hopeless prognosis rendering further treatment futile.

We also found differences regarding practices around postmortem organ donation. First, we found differences concerning the removal of the ventricular drain. Our questionnaire did not assess in-depth the reasons why some centers opted to discontinue drainage and remove the ventricular drain as compared to maintaining the device in place, and how such continued intervention was incorporated into the care plan. Second, we found differences with regard to the possibility for organ donation after circulatory arrest. These results are in line with previous literature [21, 22]. The ventricular drain (mentioned earlier in this paragraph) seemed to be removed more often in centers where donation after circulatory arrest was not possible. If this turns out to be general practice, this might indicate the need for reevaluation of organ donation after circulatory arrest in order to prevent future burdensome care. For international figures on donation and transplantation, we refer the reader to the Newsletter Transplant 2017 produced by the Council of Europe of the European Committee [23]. There are no specific figures available for the centers involved in the Collaborative European NeuroTrauma Effectiveness Research in Traumatic Brain Injury (CENTER-TBI) study. Although the CENTER-TBI study includes important neurotrauma centers, we do not know to what extent these centers are responsible for the investigated figures of the Council of Europe. For the countries involved in our study, the number of donations after brain death in 2016 varied between 1.3 per million inhabitants (Bosnia and Herzegovina) and 33.1 per million inhabitants (Spain) [23]. Third, we found differences in hands-off times needed after circulatory arrest in order to declare a patient dead. This could indicate a lack of clear evidence on the exact time needed to be sure the brain has irreversibly lost its function.

Some of the differences appear region specific, but for other aspects we found variation between centers within a single region. Differences were even noted between regions participating in Eurotransplant, an organization that aims to optimally distribute organs by transplanting across national borders, when no matching recipient is available on the waiting list in the donor's country. Eurotransplant covers part of Europe, and includes eight countries: Austria, Belgium, Croatia, Germany, Hungary, the Netherlands, Luxembourg, and Slovenia. The differences found pertained to all topics covered in this study.

Present-day medicine is said to be affected by the cultural climate of the society in which it exists [24].
This may indicate that differences in culture could explain some of the observed variation. Other results, such as possibilities for organ donation after circulatory arrest, suggest that variations have a more legal or regulatory basis. Observed within-region differences which suggest a more legal or regulatory basis raise questions regarding the level of enforcement of pertinent laws, and may indicate a lack of knowledge, regulatory implementation, or ambiguous legislation.

This study has several limitations that should be considered when interpreting the results. First, the participating neurotrauma centers represent a select group. The data obtained may therefore not be representative for all neurotrauma centers within the geographical areas studied. Second, our sample size made it difficult to apply more advanced statistics, such as a chi-square test, cluster analysis, and multidimensional scaling. Third, the results are based on the perceptions of practices reported by specific investigators rather than on clinical data. The CENTER-TBI study will further clarify actual practices around brain death and postmortem organ donation by analyzing clinical data. Fourth, investigators may have interpreted some questions incorrectly because a questionnaire does not always permit the nuances appropriate for clinical practice. In clinical practice, potential alternative options are both more numerous and complex than can be captured by a questionnaire. Last, investigators may have presented (even unwittingly) a more favorable image or presented individual preferences instead of the general policy in a center that we asked for.

Future research should focus on extending this study to a larger group of neurotrauma centers across the world in order to examine (in more advanced statistics) whether our results also apply to other centers. Furthermore, it would be interesting to study the origin of the differences found (e.g., cultural differences and differences pertaining to legislation). The complexity of some of the drivers of reported practice makes the case for mixed methods approaches to this problem, with a potentially substantive role for qualitative research methods. These strategies are important in order to inform preferred approaches to improve harmonization in neurotrauma centers across Europe and Israel.

Most importantly, current dialogs should be continued, and we hope that our findings may provide a basis toward further harmonization of practices around brain death and postmortem organ donation.

\section{Conclusion}

This study showed both agreement and some regional differences regarding practices around brain death and postmortem organ donation. We hope our results help quantify and understand potential differences, and 
provide impetus for current dialogs toward further harmonization of practices around brain death and postmortem organ donation.

\section{Additional file}

Additional file 1: Provider profiling questionnaires used for this study (Questionnaires 1, 7, and 8). (PDF 596 kb)

\section{Abbreviations}

AAN: American Academy of Neurology; BDD: Brain death determination; CENTER-TBI: Collaborative European NeuroTrauma Effectiveness Research in Traumatic Brain Injury; CSF: Cerebrospinal fluid; ECG: Electrocardiography; GCS: Glasgow Coma Scale; ICU: Intensive care unit; LSM: Life-sustaining measures; TBI: Traumatic brain injury; UK: United Kingdom

\section{Acknowledgements}

Cecilia Ackerlund ${ }^{1}$, Hadie Adams², Vanni Agnoletti ${ }^{3}$, Judith Allanson ${ }^{4}$, Krisztina Amrein $^{5}$, Norberto Andaluz ${ }^{6}$, Nada Andelic ${ }^{7}$, Lasse Andreassen ${ }^{8}$, Azasevac Antun ${ }^{9}$, Audny Anke ${ }^{10}$, Anna Antoni ${ }^{11}$, Hilko Ardon ${ }^{12}$, Gérard Audibert ${ }^{13}$, Kaspars Auslands ${ }^{14}$, Philippe Azouvi ${ }^{15}$, Maria Luisa Azzolini ${ }^{16}$, Camelia Baciu ${ }^{17}$, Rafael Badenes ${ }^{18}$, Ronald Bartels ${ }^{19}$, Pál Barzó ${ }^{20}$, Ursula Bauerfeind ${ }^{21}$, Romuald Beauvais $^{22}$, Ronny Beer ${ }^{23}$, Francisco Javier Belda ${ }^{18}$, Bo-Michael Bellander ${ }^{24}$, Antonio Belli ${ }^{25}$, Rémy Bellier ${ }^{26}$, Habib Benali ${ }^{27}$, Thierry Benard ${ }^{26}$, Maurizio Berardino $^{28}$, Luigi Beretta ${ }^{16}$, Christopher Beynon ${ }^{29}$, Federico Bilotta ${ }^{18}$, Harald Binder $^{11}$, Erta Biqiri ${ }^{17}$, Morten Blaabjerg ${ }^{30}$, Hugo den Boogert ${ }^{19}$, Pierre Bouzat $^{31}$, Peter Bragge ${ }^{32}$, Alexandra Brazinova ${ }^{33}$, Vibeke Brinck ${ }^{34}$, Joanne Brooker $^{35}$, Camilla Brorsson ${ }^{36}$, Andras Buki ${ }^{37}$, Monika Bullinger ${ }^{38}$, Emiliana Calappi $^{39}$, Maria Rosa Calvi ${ }^{16}$, Peter Cameron ${ }^{40}$, Guillermo Carbayo Lozano ${ }^{41}$, Marco Carbonara ${ }^{39}$, Elsa Carise ${ }^{26}$, K. Carpenter ${ }^{42}$, Ana M. Castaño-León ${ }^{43}$, Francesco Causin ${ }^{44}$, Giorgio Chevallard ${ }^{17}$, Arturo Chieregato ${ }^{17}$, Giuseppe Citerio $^{45,46}$, Maryse Cnossen ${ }^{47}$, Mark Coburn ${ }^{48}$, Jonathan Coles ${ }^{49}$, Lizzie ColesKemp ${ }^{50}$, Johnny Collett ${ }^{50}$, Jamie D. Cooper ${ }^{51}$, Marta Correia ${ }^{52}$, Amra Covic ${ }^{53}$, Nicola Curry ${ }^{54}$, Endre Czeiter ${ }^{55}$, Marek Czosnyka ${ }^{56}$, Claire Dahyot-Fizelier ${ }^{26}$, François Damas ${ }^{57}$, Pierre Damas ${ }^{58}$, Helen Dawes ${ }^{59}$, Véronique De Keyser ${ }^{60}$ Francesco Della Corte ${ }^{61}$, Bart Depreitere ${ }^{62}$, Godard C. W. de Ruiter ${ }^{63}$, Dula Dilvesi ${ }^{9}$, Shenghao Ding ${ }^{64}$, Diederik Dippel ${ }^{65}$, Abhishek Dixit ${ }^{66}$, Emma Donoghue $^{40}$, Jens Dreier ${ }^{67}$, Guy-Loup Dulière ${ }^{57}$, George Eapen ${ }^{68}$, Heiko Engemann ${ }^{53}$, Ari Ercole ${ }^{66}$, Patrick Esser ${ }^{59}$, Erzsébet Ezer ${ }^{69}$, Martin Fabricius ${ }^{70}$, Valery L. Feigin ${ }^{71}$, Junfeng Feng ${ }^{64}$, Kelly Foks ${ }^{65}$, Francesca Fossi ${ }^{17}$, Gilles Francony ${ }^{31}$, Ulderico Freo ${ }^{72}$, Shirin Frisvold ${ }^{73}$, Alex Furmanov ${ }^{74}$, Pablo Gagliardo ${ }^{75}$, Damien Galanaud $^{27}$, Dashiell Gantner ${ }^{40}$, Guoyi Gao ${ }^{76}$, Karin Geleijns ${ }^{42}$, Pradeep George ${ }^{1}$, Alexandre Ghuysen ${ }^{77}$, Lelde Giga ${ }^{78}$, Benoit Giraud $^{26}$, Ben Glocker ${ }^{79}$, Jagos Golubovic ${ }^{9}$, Pedro A. Gomez ${ }^{43}$, Francesca Grossi $^{61}$, Russell L. Gruen ${ }^{80}$, Deepak Gupta ${ }^{81}$, Juanita A. Haagsma ${ }^{47}$, lain Haitsma ${ }^{82}$, Jed A. Hartings ${ }^{83}$, Raimund Helbok ${ }^{23}$, Eirik Helseth ${ }^{84}$, Daniel Hertle $^{30}$, Astrid Hoedemaekers ${ }^{85}$, Stefan Hoefer ${ }^{53}$, Lindsay Horton ${ }^{86}$, Jilske Huijben ${ }^{47}$, Peter J. Hutchinson ${ }^{2}$, Asta Kristine Håberg ${ }^{87}$, Bram Jacobs ${ }^{88}$, Stefan Jankowski $^{68}$, Mike Jarrett ${ }^{34}$, Bojan Jelaca ${ }^{9}$, Ji-yao Jiang ${ }^{76}$, Kelly Jones ${ }^{89}$, Konstantinos Kamnitsas ${ }^{79}$, Mladen Karan ${ }^{6}$, Ari Katila ${ }^{90}$, Maija Kaukonen ${ }^{91}$, Thomas Kerforne ${ }^{26}$, Riku Kivisaari ${ }^{91}$, Angelos G. Kolias², Bálint Kolumbán ${ }^{92}$, Erwin Kompanje ${ }^{93}$, Ksenija Kolundzija ${ }^{94}$, Daniel Kondziella ${ }^{70}$, Lars-Owe Koskinen $^{36}$, Noémi Kovács ${ }^{92}$, Alfonso Lagares ${ }^{43}$, Linda Lanyon', Steven Laureys ${ }^{95}$, Fiona Lecky ${ }^{96}$, Christian Ledig ${ }^{79}$, Rolf Lefering ${ }^{97}$, Valerie Legrand ${ }^{98}$, Jin Lei ${ }^{64}$, Leon Levi ${ }^{99}$, Roger Lightfoot ${ }^{100}$, Hester Lingsma ${ }^{47}$, Dirk Loeckx ${ }^{101}$, Angels Lozano $^{18}$, Andrew I. R. Maas ${ }^{60}$, Stephen MacDonald ${ }^{102}$, Marc Maegele ${ }^{103}$, Marek Majdan ${ }^{33}$, Sebastian Major ${ }^{104}$, Alex Manara ${ }^{105}$, Geoffrey Manley ${ }^{106}$ ', Didier Martin ${ }^{107}$, Leon Francisco Martin ${ }^{101}$, Costanza Martino ${ }^{3}$, Armando Maruenda ${ }^{18}$, Hugues Maréchal $^{57}$, Alessandro Masala ${ }^{3}$, Julia Mattern ${ }^{29}$, Charles McFadyen ${ }^{66}$, Catherine McMahon ${ }^{108}$, Béla Melegh ${ }^{109}$, David Menon ${ }^{66}$, Tomas Menovsky ${ }^{60}$, Cristina Morganti-Kossmann ${ }^{110}$, Davide Mulazzi ${ }^{39}$, Visakh Muraleedharan ${ }^{1}$, Lynnette Murray ${ }^{40}$, Holger Mühlan ${ }^{111}$, Nandesh Nair ${ }^{60}$, Ancuta Negru ${ }^{112}$, David Nelson', Virginia Newcombe ${ }^{66}$, Daan Nieboer $^{47}$ Quentin Noirhomme ${ }^{95}$, József Nyirádi ${ }^{5}$, Mauro Oddo ${ }^{113}$, Annemarie Oldenbeuving ${ }^{114}$, Matej Oresic ${ }^{115}$, Fabrizio Ortolano ${ }^{39}$, Aarno Palotie 116,117,118, Paul M. Parizel ${ }^{119}$, Adriana Patruno ${ }^{120}$, Jean-François Payen ${ }^{31}$, Natascha Perera $^{22}$, Vincent Perlbarg ${ }^{27}$, Paolo Persona ${ }^{121}$, Wilco Peul ${ }^{63}$, Anna PiippoKarjalainen ${ }^{91}$, Sébastien Pili Floury ${ }^{122}$, Matti Pirinen ${ }^{116}$, Horia Ples ${ }^{112}$, Maria Antonia Poca ${ }^{123}$, Suzanne Polinder ${ }^{4 \prime}$, Inigo Pomposo ${ }^{41}$, Jussi Posti ${ }^{90}$, Louis
Puybasset ${ }^{124}$, Andreea Radoi ${ }^{123}$, Arminas Ragauskas ${ }^{125}$, Rahul Raj ${ }^{91}$, Malinka Rambadagalla ${ }^{126}$, Ruben Real ${ }^{53}$, Veronika Rehorčíková ${ }^{33}$, Jonathan Rhodes ${ }^{127}$, Samuli Ripatti ${ }^{116}$, Saulius Rocka ${ }^{125}$, Cecilie Roe ${ }^{128}$, Olav Roise ${ }^{129}$, Gerwin Roks $^{130}$, Jonathan Rosand ${ }^{131}$, Jeffrey Rosenfeld ${ }^{110}$, Christina Rosenlund ${ }^{132}$, Guy Rosenthal $^{74}$, Rolf Rossaint ${ }^{48}$, Sandra Rossi ${ }^{121}$, Daniel Rueckert ${ }^{79}$, Martin Rusnák ${ }^{133}$, Marco Sacchi ${ }^{17}$, Barbara Sahakian ${ }^{66}$, Juan Sahuquillo' ${ }^{123}$, Oliver Sakowitz ${ }^{134,135}$, Francesca Sala ${ }^{120}$, Renan Sanchez-Porras ${ }^{134}$, Janos Sandor ${ }^{136}$, Edgar Santos ${ }^{29}$, Luminita Sasu ${ }^{61}$, Davide Savo ${ }^{120}$, Nadine Schäffer ${ }^{103}$, Inger Schipper $^{137}$, Barbara Schlößer ${ }^{21}$, Silke Schmidt ${ }^{111}$, Herbert Schoechl ${ }^{138}$, Guus Schoonman ${ }^{130}$, Rico Frederik Schou ${ }^{139}$, Elisabeth Schwendenwein ${ }^{11}$, Michael

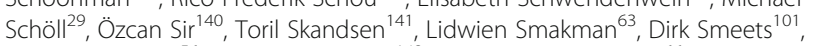
Peter Smielewski ${ }^{56}$, Abayomi Sorinola ${ }^{142}$, Emmanuel Stamatakis ${ }^{66}$, Simon Stanworth $^{54}$, Nicole Steinbüchel ${ }^{143}$, Ana Stevanovic ${ }^{48}$, Robert Stevens ${ }^{144}$, William Stewart ${ }^{145}$, Ewout W. Steyerberg ${ }^{47,146}$, Nino Stocchetti ${ }^{147}$, Nina Sundström ${ }^{36}$, Anneliese Synnot ${ }^{34,148}$, Fabio Silvio Taccone ${ }^{18}$, Riikka Takala ${ }^{90}$, Viktória Tamás ${ }^{142}$, Päivi Tanskanen ${ }^{91}$, Mark Steven Taylor ${ }^{33}$, Braden Te Ao ${ }^{71}$, Olli Tenovuo ${ }^{90}$, Ralph Telgmann ${ }^{53}$, Guido Teodorani ${ }^{149}$, Alice Theadom ${ }^{71}$, Matt Thomas $^{105}$, Dick Tibboel ${ }^{42}$, Christos Tolias ${ }^{150}$, Jean-Flory Luaba ${ }^{T}$ shibanda ${ }^{151}$, Tony Trapani ${ }^{40}$, Cristina Maria Tudora ${ }^{112}$, Peter Vajkoczy ${ }^{67}$, Shirley Vallance ${ }^{43}$, Egils Valeinis ${ }^{78}$, Gregory Van der Steen ${ }^{60}$, Mathieu van der Jagt $^{152}$, Joukje van der Naalt ${ }^{88}$, Jeroen T. J. M. van Dijck ${ }^{63}$, Thomas A. van Essen $^{63}$, Wim Van Hecke ${ }^{101}$, Caroline van Heugten ${ }^{59}$, Dominique Van Praag ${ }^{60}$ Thijs Vande Vyvere ${ }^{101}$, Julia Van Waesberghe ${ }^{48}$, Audrey Vanhaudenhuyse ${ }^{27,95}$, Alessia Vargiolu ${ }^{120}$, Emmanuel Vega ${ }^{153}$, Kimberley Velt ${ }^{47}$, Jan Verheyden ${ }^{101}$, Paul M. Vespa ${ }^{154}$, Anne Vik ${ }^{155}$, Rimantas Vilcinis ${ }^{156}$, Giacinta Vizzino ${ }^{17}$, Carmen Vleggeert-Lankamp ${ }^{63}$, Victor Volovici ${ }^{82}$, Daphne Voormolen ${ }^{47}$, Peter Vulekovic $^{9}$, Zoltán Vámos ${ }^{69}$, Derick Wade ${ }^{59}$, Kevin K. W. Wang ${ }^{157}$, Lei Wang ${ }^{64}$, Lars Wessels ${ }^{158}$, Eno Wildschut ${ }^{42}$, Guy Williams ${ }^{66}$, Lindsay Wilson ${ }^{86}$, Maren K. L. Winkler $^{104}$, Stefan Wolf ${ }^{158}$, Peter Ylén ${ }^{159}$, Alexander Younsi ${ }^{29}$, Menashe Zaaroor $^{99}$, Yang Zhihui ${ }^{160}$, Agate Ziverte ${ }^{78}$, Fabrizio Zumbo ${ }^{3}$.

${ }^{1}$ Karolinska Institutet, INCF International Neuroinformatics Coordinating Facility, Stockholm, Sweden.

2 Division of Neurosurgery, Department of Clinical Neurosciences,

Addenbrooke's Hospital \& University of Cambridge, Cambridge, UK.

${ }^{3}$ Department of Anesthesia \& Intensive Care, M. Bufalini Hospital,

Cesena, Italy.

${ }^{4}$ Department of Clinical Neurosciences, Addenbrooke's Hospital \& University of Cambridge, Cambridge, UK.

5 János Szentágothai Research Centre, University of Pécs, Pécs, Hungary.

${ }^{6}$ University of Cincinnati, Cincinnati, OH, USA.

${ }^{7}$ Division of Surgery and Clinical Neuroscience, Department of Physical Medicine and Rehabilitation, Oslo University Hospital and University of Oslo, Oslo, Norway.

${ }^{8}$ Department of Neurosurgery, University Hospital Northern Norway, Tromsø, Norway.

${ }^{9}$ Department of Neurosurgery, Clinical Centre of Vojvodina, Faculty of Medicine, University of Novi Sad, Novi Sad, Serbia.

${ }^{10}$ Department of Physical Medicine and Rehabilitation, University Hospital Northern Norway.

11 Trauma Surgery, Medical University Vienna, Vienna, Austria.

12 Department of Neurosurgery, Elisabeth-TweeSteden Ziekenhuis, Tilburg, the Netherlands.

${ }^{13}$ Department of Anesthesiology \& Intensive Care, University Hospital Nancy, Nancy, France.

${ }^{14}$ Riga Eastern Clinical University Hospital, Riga, Latvia.

15 Raymond Poincaré Hospital, Assistance Publique-Hopitaux de Paris, Paris, France.

${ }^{16}$ Department of Anesthesiology \& Intensive Care, S Raffaele University Hospital, Milan, Italy.

${ }^{17}$ Neurolntensive Care, Niguarda Hospital, Milan, Italy.

${ }^{18}$ Department Anesthesiology and Surgical-Trauma Intensive Care, Hospital Clinic Universitari de Valencia, Spain.

${ }^{19}$ Department of Neurosurgery, Radboud University Medical Center, Nijmegen, the Netherlands.

20 Department of Neurosurgery, University of Szeged, Szeged, Hungary.

${ }^{21}$ Institute for Transfusion Medicine (ITM), Witten/Herdecke University, Cologne, Germany.

22 International Projects Management, ARTTIC, München, Germany.

${ }^{23}$ Department of Neurology, Neurological Intensive Care Unit, Medical University of Innsbruck, Innsbruck, Austria. 
${ }^{24}$ Department of Neurosurgery \& Anesthesia \& Intensive Care Medicine, Karolinska University Hospital, Stockholm, Sweden.

${ }^{25}$ NIHR Surgical Reconstruction and Microbiology Research Centre, Birmingham, UK.

${ }^{26}$ Intensive Care Unit, CHU Poitiers, Poitiers, France.

${ }^{27}$ Anesthesie-Réanimation, Assistance Publique-Hopitaux de Paris, Paris, France.

${ }^{28}$ Department of Anesthesia \& ICU, AOU Città della Salute e della Scienza di Torino-Orthopedic and Trauma Center, Torino, Italy.

${ }^{29}$ Department of Neurosurgery, University Hospital Heidelberg, Heidelberg, Germany.

30 Department of Neurology, Odense University Hospital, Odense, Denmark.

31 Department of Anesthesiology \& Intensive Care, University Hospital of Grenoble, Grenoble, France.

32 BehaviourWorks Australia, Monash Sustainability Institute, Monash University, VIC, Australia.

${ }^{33}$ Department of Public Health, Faculty of Health Sciences and Social Work, Trnava University, Trnava, Slovakia.

34 Quesgen Systems Inc., Burlingame, CA, USA.

35 Australian \& New Zealand Intensive Care Research Centre, Department of Epidemiology and Preventive Medicine, School of Public Health and Preventive Medicine, Monash University, Melbourne, Australia.

36 Department of Neurosurgery, Umea University Hospital, Umea, Sweden.

${ }^{37}$ Department of Neurosurgery, University of Pecs and MTA-PTE Clinical Neuroscience MR Research Group and Janos Szentagothai Research Centre, University of Pecs, Hungarian Brain Research Program, Pecs, Hungary.

38 Department of Medical Psychology, Universitätsklinikum HamburgEppendorf, Hamburg, Germany.

${ }^{39}$ Neuro ICU, Fondazione IRCCS Cà Granda Ospedale Maggiore Policlinico, Milan, Italy.

${ }^{40}$ ANZIC Research Centre, Monash University, Department of Epidemiology and Preventive Medicine, Melbourne, Vitoria, Australia.

${ }^{41}$ Department of Neurosurgery, Hospital of Cruces, Bilbao, Spain.

${ }^{42}$ Intensive Care and Department of Pediatric Surgery, Erasmus University Medical Center, Sophia Children's Hospital, Rotterdam, the Netherlands.

${ }^{43}$ Department of Neurosurgery, Hospital Universitario 12 de Octubre, Madrid, Spain

44 Department of Neuroscience, Azienda Ospedaliera Università di Padova, Padova, Italy.

${ }^{45}$ Neurolntensive Care, ASST di Monza, Monza, Italy.

${ }^{46}$ School of Medicine and Surgery, Università Milano Bicocca, Milan, Italy.

47 Department of Public Health, Erasmus University Medical Center, Rotterdam, the Netherlands.

48 Department of Anaesthesiology, University Hospital of Aachen, Aachen, Germany.

49 Department of Anesthesia \& Neurointensive Care, Cambridge University Hospital NHS Foundation Trust, Cambridge, UK.

${ }^{50}$ Movement Science Group, Oxford Institute of Nursing, Midwifery and Allied Health Research, Oxford Brookes University, Oxford, UK.

51 School of Public Health \& PM, Monash University and The Alfred Hospital, Melbourne, VIC, Australia.

52 Radiology/MRI Department, MRC Cognition and Brain Sciences Unit, Cambridge, UK.

53 Institute of Medical Psychology and Medical Sociology, Universitätsmedizin Göttingen, Göttingen, Germany.

54 Oxford University Hospitals NHS Trust, Oxford, UK.

55 Department of Neurosurgery, University of Pecs and MTA-PTE Clinical Neuroscience MR Research Group and Janos Szentagothai Research Centre, University of Pecs, Hungarian Brain Research Program (Grant No. KTIA 13 NAP-A-II/8), Pecs, Hungary.

${ }^{56}$ Brain Physics Lab, Division of Neurosurgery, Department of Clinical Neurosciences, University of Cambridge, Addenbrooke's Hospital, Cambridge, UK

57 Intensive Care Unit, CHR Citadelle, Liège, Belgium.

58 Intensive Care Unit, CHU, Liège, Belgium.

59 Movement Science Group, Faculty of Health and Life Sciences, Oxford Brookes University, Oxford, UK.

60 Department of Neurosurgery, Antwerp University Hospital and University of Antwerp, Edegem, Belgium.

61 Department of Anesthesia \& Intensive Care, Maggiore Della Carità Hospital, Novara, Italy.

${ }^{62}$ Department of Neurosurgery, University Hospitals Leuven, Leuven, Belgium.
63 Department of Neurosurgery, Leiden University Medical Center, Leiden, the Netherlands and Departmentt of Neurosurgery, Medical Center Haaglanden, The Hague, the Netherlands.

${ }^{64}$ Department of Neurosurgery, Renji Hospital, Shanghai Jiaotong University School of Medicine, Shanghai, China.

65 Department of Neurology, Erasmus University Medical Center, Rotterdam, the Netherlands.

${ }^{66}$ Division of Anaesthesia, University of Cambridge, Addenbrooke's Hospital, Cambridge, UK.

${ }^{67}$ Neurologie, Neurochirurgie und Psychiatrie, Charité-Universitätsmedizin Berlin, Berlin, Germany.

${ }^{68}$ Neurointensive Care, Sheffield Teaching Hospitals NHS Foundation Trust, Sheffield, UK

69 Department of Anaesthesiology and Intensive Therapy, University of Pécs, Pécs, Hungary.

70 Departments of Neurology, Clinical Neurophysiology and Neuroanesthesiology, Region Hovedstaden Rigshospitalet, Copenhagen, Denmark

71 National Institute for Stroke and Applied Neurosciences, Faculty of Health and Environmental Studies, Auckland University of Technology, Auckland, New Zealand.

72 Department of Medicine, Azienda Ospedaliera Università di Padova, Padova, Italy.

73 Department of Anesthesiology and Intensive Care, University Hospital Northern Norway, Tromsø, Norway.

${ }^{74}$ Department of Neurosurgery, Hadassah-Hebrew University Medical Center, Jerusalem, Israel.

${ }^{75}$ Fundación Instituto Valenciano de Neurorrehabilitación (FIVAN), Valencia, Spain.

${ }^{76}$ Department of Neurosurgery, Shanghai Renji Hospital, Shanghai Jiaotong University/School of Medicine, Shanghai, China.

77 Emergency Department, CHU, Liège, Belgium.

78 Pauls Stradins Clinical University Hospital, Riga, Latvia.

79 Department of Computing, Imperial College London, London, UK.

80 Lee Kong Chian School of Medicine, Nanyang Technological University, Singapore; and Central Clinical School, Monash University, Melbourne, Victoria, Australia.

${ }^{81}$ Department of Neurosurgery, Neurosciences Centre \& JPN Apex Trauma Centre, All India Institute of Medical Sciences, New Delhi, India.

82 Department of Neurosurgery, Erasmus University Medical Center, Rotterdam, the Netherlands.

${ }^{83}$ Department of Neurosurgery, University of Cincinnati, Cincinnati, OH, USA.

84 Department of Neurosurgery, Oslo University Hospital, Oslo, Norway.

${ }^{85}$ Department of Intensive Care Medicine, Radboud University Medical Centern,

Nijmegen, the Netherlands.

${ }^{86}$ Division of Psychology, University of Stirling, Stirling, UK.

${ }^{87}$ Department of Medical Imaging, St. Olavs Hospital and Department of Neuroscience, Norwegian University of Science and Technology, Trondheim, Norway.

${ }^{88}$ Department of Neurology, University Medical Center Groningen, Groningen, the Netherlands.

${ }^{89}$ National Institute for Stroke \& Applied Neurosciences of the AUT University, Auckland, New Zealand.

90 Rehabilitation and Brain Trauma, Turku University Central Hospital and University of Turku, Turku, Finland.

${ }^{91}$ Helsinki University Central Hospital, Helsinki, Finland.

92 Hungarian Brain Research Program-Grant No. KTIA 13 NAP-A-II/8, University of Pécs, Pécs, Hungary.

93 Department of Intensive Care and Department of Ethics and Philosophy of Medicine, Erasmus University Medical Center, Rotterdam, the Netherlands.

94 Department of Psychiatry, Clinical centre of Vojvodina, Faculty of Medicine, University of Novi Sad, Novi Sad, Serbia.

${ }^{95}$ Cyclotron Research Center, University of Liège, Liège, Belgium.

${ }^{96}$ Emergency Medicine Research in Sheffield, Health Services Research Section, School of Health and Related Research (ScHARR), University of Sheffield, Sheffield, UK.

${ }^{97}$ Institute of Research in Operative Medicine (IFOM), Witten/Herdecke University, Cologne, Germany.

${ }^{98}$ VP Global Project Management CNS, ICON, Paris, France.

99 Department of Neurosurgery, Rambam Medical Center, Haifa, Israel.

${ }^{100}$ Department of Anesthesiology \& Intensive Care, University Hospitals Southampton NHS Trust, Southampton, UK.

101 icoMetrix NV, Leuven, Belgium. 
${ }^{102}$ Cambridge University Hospitals, Cambridge, UK.

103 Cologne-Merheim Medical Center (CMMC), Department of Traumatology, Orthopedic Surgery and Sportmedicine, Witten/Herdecke University, Cologne, Germany.

104 Centrum für Schlaganfallforschung, Charité-Universitätsmedizin Berlin, Berlin, Germany.

105 Intensive Care Unit, Southmead Hospital, Bristol, Bristol, UK.

106 Department of Neurological Surgery, University of California, San Francisco, CA, USA.

107 Department of Neurosurgery, CHU, Liège, Belgium.

108 Department of Neurosurgery, The Walton Centre NHS Foundation Trust, Liverpool, UK.

${ }^{109}$ Department of Medical Genetics, University of Pécs, Pécs, Hungary.

110 National Trauma Research Institute, The Alfred Hospital, Monash University, Melbourne, VIC, Australia.

111 Department Health and Prevention, University Greifswald, Greifswald, Germany.

112 Department of Neurosurgery, Emergency County Hospital Timisoara, Timisoara, Romania.

113 Centre Hospitalier Universitaire Vaudois, Lausanne, Zwitserland.

114 Department of Intensive Care, Elisabeth-TweeSteden Ziekenhuis, Tilburg, the Netherlands.

115 Department of Systems Medicine, Steno Diabetes Center, Gentofte, Denmark

116 Institute for Molecular Medicine Finland, University of Helsinki, Helsinki, Finland.

117 Analytic and Translational Genetics Unit, Department of Medicine; Psychiatric \& Neurodevelopmental Genetics Unit, Department of Psychiatry; Department of Neurology, Massachusetts General Hospital, Boston, MA, USA

118 Program in Medical and Population Genetics; The Stanley Center for Psychiatric Research, The Broad Institute of MIT and Harvard, Cambridge, MA, USA.

${ }^{119}$ Department of Radiology, Antwerp University Hospital and University of Antwerp, Edegem, Belgium.

${ }^{120}$ Neurolntensive Care Unit, Department of Anesthesia \& Intensive Care, ASST di Monza, Monza, Italy.

121 Department of Anesthesia \& Intensive Care, Azienda Ospedaliera Università di Padova, Padova, Italy.

122 Intensive Care Unit, CHRU de Besançon, Besançon, France.

123 Department of Neurosurgery, Vall d'Hebron University Hospital, Barcelona, Spain.

124 Department of Anesthesiology and Critical Care, Pitié-Salpêtrière Teaching Hospital, Assistance Publique, Hôpitaux de Paris and University Pierre et Marie Curie, Paris, France.

125 Department of Neurosurgery, Kaunas University of technology and Vilnius University, Vilnius, Lithuania.

${ }^{126}$ Rezekne Hospital, Rezekne, Latvia

127 Department of Anaesthesia, Critical Care \& Pain Medicine NHS Lothian \& University of Edinburg, Edinburgh, UK.

${ }^{128}$ Department of Physical Medicine and Rehabilitation, Oslo University Hospital/University of Oslo, Oslo, Norway.

${ }^{129}$ Division of Surgery and Clinical Neuroscience, Oslo University Hospital, Oslo, Norway.

130 Department of Neurology, Elisabeth-TweeSteden Ziekenhuis, Tilburg, the Netherlands.

131 Broad Institute, Cambridge, MA; Harvard Medical School, Boston, MA; and Massachusetts General Hospital, Boston, MA, USA

132 Department of Neurosurgery, Odense University Hospital, Odense, Denmark

133 International Neurotrauma Research Organisation, Vienna, Austria.

134 Klinik für Neurochirurgie, Klinikum Ludwigsburg, Ludwigsburg, Germany.

135 University Hospital Heidelberg, Heidelberg, Germany.

${ }^{136}$ Division of Biostatistics and Epidemiology, Department of Preventive Medicine, University of Debrecen, Debrecen, Hungary.

${ }^{137}$ Department of Traumasurgery, Leiden University Medical Center, Leiden, the Netherlands.

138 Department of Anaesthesiology and Intensive Care, AUVA Trauma Hospital, Salzburg, Austria.

${ }^{139}$ Department of Neuroanesthesia and Neurointensive Care, Odense University Hospital, Odense, Denmark.

140 Department of Emergency Care Medicine, Radboud University Medical Center, Nijmegen, the Netherlands.
${ }^{141}$ Department of Physical Medicine and Rehabilitation, St. Olavs Hospital and Department of Neuroscience, Norwegian University of Science and Technology, Trondheim, Norway.

142 Department of Neurosurgery, University of Pécs, Pécs, Hungary.

143 Universitätsmedizin Göttingen, Göttingen, Germany.

144 Division of Neuroscience Critical Care, John Hopkins University School of Medicine, Baltimore, MD, USA.

145 Department of Neuropathology, Queen Elizabeth University Hospital and University of Glasgow, Glasgow, UK.

${ }^{146}$ Department of Biomedical Data Sciences, Leiden University Medical Center, Leiden, the Netherlands.

147 Department of Pathophysiology and Transplantation, Milan University, and Neuroscience ICU, Fondazione IRCCS Cà Granda Ospedale Maggiore Policlinico, Milan, Italy.

${ }^{148}$ Cochrane Consumers and Communication Review Group, Centre for Health Communication and Participation, School of Psychology and Public Health, La Trobe University, Melbourne, Australia.

149 Department of Rehabilitation, M. Bufalini Hospital, Cesena, Italy.

150 Department of Neurosurgery, Kings College London, London, UK.

${ }^{151}$ Radiology/MRI Department, CHU, Liège, Belgium.

152 Department of Intensive Care, Erasmus University Medical Center, Rotterdam, the Netherlands.

153 Department of Anesthesiology-Intensive Care, Lille University Hospital, Lille, France.

154 Director of Neurocritical Care, University of California, Los Angeles, CA, USA.

155 Department of Neurosurgery, St. Olavs Hospital and Department of Neuroscience, Norwegian University of Science and Technology, Trondheim, Norway.

156 Department of Neurosurgery, Kaunas University of Health Sciences, Kaunas, Lithuania.

157 Department of Psychiatry, University of Florida, Gainesville, FL, USA.

158 Interdisciplinary Neuro Intensive Care Unit, Charité-Universitätsmedizin Berlin, Berlin, Germany.

${ }^{159}$ VTT Technical Research Centre, Tampere, Finland.

160 University of Florida, Gainesville, FL, USA.

\section{Funding}

Data used in preparation of this manuscript were obtained in the context of the CENTER-TBI study, a large collaborative project, supported by the Framework 7 program of the European Union (602150). The funder had no role in the design of the study, the collection, analysis, and interpretation of data, or in writing the manuscript.

DKM was supported by a Senior Investigator Award from the National Institute for Health Research (UK). The funder had no role in the design of the study, the collection, analysis, and interpretation of data, or in writing the manuscript.

\section{Availability of data and materials}

There are legal constraints that prohibit us from making the data publicly available. Since there are only a limited number of centers per country included in this study (for two countries only one center), data will be identifiable. Readers may contact Dr Erwin J. O. Kompanje (e.j.o.kompanje@erasmusmc.nl) for reasonable requests for the data.

\section{Authors' contributions}

EvV analyzed the data and drafted the manuscript and the supplementary tables. All coauthors gave feedback on the manuscript. EJOK supervised the project. All coauthors were involved in the design of the survey and the distribution of the survey. All coauthors gave feedback on (and approved) the final version of the manuscript.

\section{Ethics approval and consent to participate}

Not applicable since no patients participated, and the centers have given consent by completing the questionnaire.

\section{Consent for publication}

Not applicable.

\section{Competing interests}

The authors declare that they have no competing interests. 


\section{Publisher's Note}

Springer Nature remains neutral with regard to jurisdictional claims in published maps and institutional affiliations.

\section{Author details}

${ }^{1}$ Department of Intensive Care, Erasmus University Medical Center, Rotterdam, the Netherlands. ${ }^{2}$ Center for Medical Decision Making, Department of Public Health, Erasmus University Medical Center, Rotterdam, the Netherlands. ${ }^{3}$ Department of Medical Ethics and Philosophy of Medicine, Erasmus University Medical Center, Rotterdam, the Netherlands. ${ }^{4}$ Department of Neurosurgery, Antwerp University Hospital and University of Antwerp, Edegem, Belgium. ${ }^{5}$ Department of Anaesthesia, University of Cambridge, Cambridge, UK. 'School of Medicine and Surgery, University of Milan-Bicocca, Milan, Italy. ${ }^{7}$ San Gerardo Hospital, ASST-Monza, Monza, Italy. ${ }^{8}$ Department of Physiopathology and Transplantation, Milan University, Milan, Italy. ${ }^{9}$ Neuro ICU Fondazione IRCCS Cà Granda Ospedale Maggiore Policlinico Milano, Milan, Italy. ${ }^{10}$ Department of Neurosurgery, Leiden University Medical Center, Leiden, the Netherlands.

\section{Received: 2 May 2018 Accepted: 15 October 2018}

\section{Published online: 16 November 2018}

\section{References}

1. Mollaret P, Goulon M. Le coma dépassé (mémoire prélininaire). Rev Neurol (Paris). 1959:101:3-15.

2. A definition of irreversible coma. Report of the Ad Hoc Committee of the Harvard Medical School to Examine the Definition of Brain Death. JAMA. 1968;205(6):337-40.

3. Guidelines for the determination of death. Report of the medical consultants on the diagnosis of death to the President's Commission for the Study of Ethical Problems in Medicine and Biomedical and Behavioral Research. JAMA. 1981;246(19):2184-6.

4. Practice parameters for determining brain death in adults (summary statement). The Quality Standards Subcommittee of the American Academy of Neurology. Neurology. 1995;45(5):1012-4.

5. Wijdicks EF, Varelas PN, Gronseth GS, Greer DM. Evidence-based guideline update: determining brain death in adults: Report of the Quality Standards Subcommittee of the American Academy of Neurology. Neurology. 2010;74(23):1911-8.

6. Academy of Medical Royal Colleges (2008) A code of practice for the diagnosis and confirmation of death. http://aomrc.org.uk/wp-content/ uploads/2016/04/Code_Practice_Confirmation_Diagnosis_Death_1008-4.pdf Accessed 5 Nov 2018

7. Maas Al, Menon DK, Steyerberg EW, Citerio G, Lecky F, Manley GT, Hill S, Legrand V, Sorgner A. Collaborative European NeuroTrauma Effectiveness Research in Traumatic Brain Injury (CENTER-TBI): a prospective longitudinal observational study. Neurosurgery. 2015;76(1):67-80.

8. Maas AIR, Menon DK, Adelson PD, Andelic N, Bell MJ, Belli A, Bragge P Brazinova A, Buki A, Chesnut RM, Citerio G, Coburn M, Cooper DJ, Crowder AT, Czeiter E, Czosnyka M, Diaz-Arrastia R, Dreier JP, Duhaime AC, Ercole A, van Essen TA, Feigin VL, Gao G, Giacino J, Gonzalez-Lara LE, Gruen RL, Gupta D, Hartings JA, Hill S, Jiang JY, Ketharanathan N, Kompanje EJO, Lanyon L, Laureys S, Lecky F, Levin H, Lingsma HF, Maegele M, Majdan M, Manley G, Marsteller J, Mascia L, McFadyen C, Mondello S, Newcombe V, Palotie A, Parizel PM, Peul W, Piercy J, Polinder S, Puybasset L, Rasmussen TE, Rossaint R, Smielewski P, Soderberg J, Stanworth SJ, Stein MB, von Steinbuchel N, Stewart W, Steyerberg EW, Stocchetti N, Synnot A, Te Ao B, Tenovuo O, Theadom A, Tibboel D, Videtta W, Wang KKW, Williams WH, Wilson L, Yaffe K. Traumatic brain injury: integrated approaches to improve prevention, clinical care, and research. Lancet Neurol. 2017;16(12):987-1048.

9. Cnossen MC, Polinder S, Lingsma HF, Maas Al, Menon D, Steyerberg EW. Variation in structure and process of care in traumatic brain injury: provider profiles of European neurotrauma centers participating in the CENTER-TBI Study. PLoS One. 2016;11(8):e0161367.

10. Shemie SD, Hornby L, Baker A, Teitelbaum J, Torrance S, Young K, Capron AM, Bernat JL, Noel L. International guideline development for the determination of death. Intensive Care Med. 2014:40(6):788-97.

11. Wahlster S, Wijdicks EF, Patel PV, Greer DM, Hemphill JCI, Carone M, Mateen FJ. Brain death declaration: practices and perceptions worldwide. Neurology. 2015;84(18):1870-9.
12. Powner DJ, Hernandez M, Rives TE. Variability among hospital policies for determining brain death in adults. Crit Care Med. 2004:32(6):1284-8.

13. Hornby K, Shemie SD, Teitelbaum J, Doig C. Variability in hospital-based brain death guidelines in Canada. Can J Anaesth. 2006;53(6):613-9.

14. Greer DM, Varelas PN, Haque S, Wijdicks EF. Variability of brain death determination guidelines in leading US neurologic institutions. Neurology. 2008;70(4):284-9.

15. Shappell CN, Frank Jl, Husari K, Sanchez M, Goldenberg F, Ardelt A. Practice variability in brain death determination: a call to action. Neurology. 2013;81(23):2009-14

16. Greer DM, Wang HH, Robinson JD, Varelas PN, Henderson GV, Wijdicks EF. Variability of brain death policies in the United States. JAMA Neurol. 2016;73(2):213-8

17. Haupt WF, Rudolf J. European brain death codes: a comparison of national guidelines. J Neurol. 1999:246(6):432-7.

18. Wijdicks EF. Brain death worldwide: accepted fact but no global consensus in diagnostic criteria. Neurology. 2002;58(1):20-5.

19. Citerio G, Crippa IA, Bronco A, Vargiolu A, Smith M. Variability in brain death determination in Europe: looking for a solution. Neurocrit Care 2014:21(3):376-82

20. Wijdicks EF. The case against confirmatory tests for determining brain death in adults. Neurology. 2010;75(1):77-83.

21. Dominguez-Gil B, Haase-Kromwijk B, Van Leiden H, Neuberger J, Coene L, Morel P, Corinne A, Muehlbacher F, Brezovsky P, Costa AN, Rozental R, Matesanz R. Current situation of donation after circulatory death in European countries. Transpl Int. 2011;24(7):676-86.

22. Wind J, Faut M, van Smaalen TC, van Heurn EL. Variability in protocols on donation after circulatory death in Europe. Crit Care. 2013;17(5):R217.

23. EDQM Council of Europe. Newsletter Transplant. International figures on donation and transplantation 2016; volume 222017.

24. Payer L. Medicine \& Culture: varieties of treatment in the United States, England, West Germany, and France. H. Holt, New York; 1988 